\title{
miRNA regulation of cytotoxic effects in mouse Sertoli cells exposed to nonylphenol
}

Jin-Sung Choi ${ }^{1 \dagger}$, Jung-Hwa Oh ${ }^{1 \dagger}$, Han-Jin Park', Mi-Sun Choi ${ }^{1}$, Se-Myo Park', Seung-Jun Kang ${ }^{1}$, Moon-Ju Oh², Seung Jun Kim², Seung Yong Hwang ${ }^{2}$ and Seokjoo Yoon ${ }^{1 *}$

\begin{abstract}
Background: It is known that some environmental chemicals affect the human endocrine system. The harmful effects of endocrine disrupting chemical (EDC) nonylphenol (NP) have been studied since the 1980s. It is known that NP adversely affects physiological functions by mimicking the natural hormone 17 beta-estradiol. In the present study, we analyzed the expression of miRNAs and their target genes in mouse Sertoli TM4 cells to better understand the regulatory roles of miRNAs on Sertoli cells after NP exposure.
\end{abstract}

Methods: Mouse TM4 Sertoli cells were treated with NP for 3 or 24 h, and global gene and miRNA expression were analyzed using Agilent mouse whole genome and mouse miRNA v13 arrays.

Results: We identified genes that were $>2$-fold differentially expressed in NP-treated cells and control cells $(P<$ 0.05 ) and analyzed their functions through Gene Ontology analysis. We also identified miRNAs that were differentially expressed in NP-treated and control cells. Of the 186 miRNAs the expression of which differed between NP-treated and control cells, 59 and 147 miRNAs exhibited 1.3-fold increased or decreased expression at 3 and 24 h, respectively. Network analysis of deregulated miRNAs suggested that Ppara may regulate the expression of certain miRNAs, including miR-378, miR-125a-3p miR-20a, miR-203, and miR-101a, after exposure to NP. Additionally, comprehensive analysis of predicted target genes for miRNAs showed that the expression of genes with roles in cell proliferation, the cell cycle, and cell death were regulated by miRNA in NP-treated TM4 cells. Levels of expression of the miRNAs miR-135a* and miR-199a-5p were validated by qRT-PCR. Finally, miR-135a* target gene analysis suggests that the generation of reactive oxygen species (ROS) following exposure to NP exposure may be mediated by miR-135a* through regulation of the Wnt/beta-catenin signaling pathway.

Conclusions: Collectively, these data help to determine NP's actions on mouse TM4 Sertoli cells and increase our understanding of the molecular mechanisms underlying the adverse effects of xenoestrogens on the reproductive system.

\section{Background}

Nonylphenol (NP) is a xenobiotic compound that is generated by the degradation of nonylphenol ethoxylates (NPEs). NPEs are used worldwide as oil-soluble detergents and emulsifiers (in the production of anionic detergents), lubricants, antistatic agents, high-performance textile-scouring agents, emulsifiers for agrochemicals, antioxidants (in the manufacture of rubber and plastics), and lubricant oil additives [1]. Due to their widespread

\footnotetext{
* Correspondence: sjyoon@kitox.re.kr

+ Contributed equally

'Division of Research and Development, Korea Institute of Toxicology, 19

Shinsung-ro, Yuseong, Daejeon, 305-343, Korea

Full list of author information is available at the end of the article
}

use, significant quantities of incompletely degraded NPs reach sewage treatment works. Because of its high hydrophobicity, low solubility, and accumulation in the environment, NP is found in many parts of the world in rivers, water, soil, groundwater, sediment, the atmosphere, sewage sludge, and even drinking water. Because of its toxic effects, it has been banned in Canada and the EU and is being carefully monitored in many other countries [2].

$\mathrm{NP}$ is a known disruptor of the endocrine system. It acts by mimicking natural hormones, thereby inhibiting or stimulating the endocrine system [2]. Specifically, NP mimics the natural hormone $17 \beta$-estradiol and tends to compete for estrogen receptor binding sites $[3,4]$. $17 \beta$ estradiol influences the development and maintenance of

\section{Biomed Central}

(c) 2011 Choi et al; licensee BioMed Central Ltd. This is an Open Access article distributed under the terms of the Creative Commons Attribution License (http://creativecommons.org/licenses/by/2.0), which permits unrestricted use, distribution, and reproduction in any medium, provided the original work is properly cited. 
male and female sex characteristics [5]. Recently, it was also found that NP has anti-androgenic activity and can disturb the proper function of androgens. Androgens are essential for normal development, including that of the reproductive systems in males [6]. In addition its effects on the endocrine system, NP also has immunoregulatory properties, and influences the cell cycle, apoptosis in neural stem cells, and the proliferation of breast cancer cells [1]. Like this, NP can induce the reproductive toxicity by disturbing the function of endogenous estrogens via receptor mechanism and also cause the cell death by modulating cellular mechanism via its phenolic group.

The results of several investigations suggest that NP can induce cell death by inhibiting the activity of endoplasmic reticulum $\mathrm{Ca}^{2+}$ pump [7]; however, the molecular mechanisms behind NP's actions remain unclear. To investigate the toxic mechanisms of NP in male reproductive system, we previously performed gene expression profiling using testis tissues from mice that were repeatedly exposed to NP [8]. We found that genes with roles in spermatogenesis, such as Odf1 and Sox family genes, were differentially expressed in the testes following exposure to NP. It is thought that expression of these genes may be regulated by sophisticated mechanisms involving epigenomic regulators such as miRNAs.

MicroRNAs (miRNAs) are small non-coding regulatory RNAs, about 22 nucleotides in length. They contain 2-8nucleotide sequences known as 'seed' regions that bind to completely or partially complementary sequences in the 3'-untranslated regions (3'-UTRs) of target mRNAs [9]. miRNAs regulate gene activity by repressing the translation of target mRNAs or triggering their degradation [10]. They are expressed in a wide range of tissues and during all stages of development in many species. To date, hundreds of miRNAs have been identified, each of which can regulate several genes. Computational predictions indicate that more than one third of all human genes may be miRNA targets [11]. miRNAs have been functionally linked to embryonic development, cell proliferation, differentiation, apoptosis and stress responses. Moreover, they also have been studied in the context of cancer and neurodegenerative diseases such as Alzheimer's disease and Parkinson's disease [12,13]. However, few reports have described the effects of toxicants on miRNA expression profiles, although recent investigations suggest the possible use of miRNAs as toxicity biomarkers $[14,15]$.

The aim of the present study was to investigate the effects of NP on miRNA expression. In this study, we treated in the mouse TM4 Sertoli cells with $10 \mu \mathrm{g} / \mathrm{mL}$ NP. Sertoli cells play a pivotal role in the regulation of spermatogenesis $[16,17]$ and TM4 is a well-established mouse cell line that retains Sertoli cell function. After exposing TM4 cells to NP, we monitored the expression of genes and miRNAs at early and late time point using microarrays. We performed comprehensive analyses of gene and miRNA expression to better understand the regulatory roles of miRNAs in the response to NP exposure.

\section{Methods}

\section{Cell culture and NP treatment}

Mouse TM4 Sertoli cells were obtained from the Korean Cell Line Bank (KCLB; Seoul, Korea). TM4 cells were grown at $37^{\circ} \mathrm{C}$ in a humidified $5 \% \mathrm{CO}_{2}$ atmosphere in Dulbecco's Modified Eagle Medium (DMEM) containing $10 \%$ fetal bovine serum (FBS) and antibiotics $(100 \mathrm{U} / \mathrm{mL}$ penicillin, $100 \mu \mathrm{g} / \mathrm{mL}$ streptomycin). DMEM, FBS, penicillin/streptomycin and trypsin-EDTA were obtained from HyClone (Logan, UT, USA). Cells were subcultured every 2-3 days. NP purchased from SUPELCO (Bellefonte, PA, USA) was suspended in DMSO (SigmaAldrich, St. Louis, MO, USA) and applied to TM4 cells at appropriate concentrations.

\section{Cell viability assay}

Cell viability was determined by a formazan assay using the Cell Counting Kit-8 (CCK-8) (Dojindo Laboratory, Kumanoto, Japan). TM4 cells suspended in culture medium were seeded in 24-well culture plates at a density of $1 \times 10^{5}$ cells per well. They were then washed and exposed to vehicle (control) or varying concentrations of $\mathrm{NP}$ for $24 \mathrm{~h}$. Following NP treatment, $100 \mu \mathrm{L}$ of CCK-8 solution was added to each well and the cells were incubated at $37^{\circ} \mathrm{C}$ for a further $1 \mathrm{~h}$. Absorbances at $450 \mathrm{~nm}$ were then measured using an ELISA reader (Bio-Rad, Japan). All experiments consisted of three independent replicates, each performed at least in triplicate. Data are presented as the mean \pm SD.

\section{RNA isolation}

Cells treated with $10 \mu \mathrm{g} / \mathrm{mL}$ NP for 3 or $24 \mathrm{~h}$ were harvested and total RNA extracted using the TRIzol reagent (Invitrogen, CA, USA) according to the manufacturer's instructions. RNA yield was quantified using a NanoDrop (NanoDrop, USA) and RNA quality using a 2100 Bioanalyzer (Agilent Technologies, CA, USA). Extracted RNA samples were stored at $-80^{\circ} \mathrm{C}$ prior to microarray analysis. miRNA microarray experiments were conducted within 2 days of RNA extraction.

\section{miRNA expression microarray analysis}

miRNA microarray analysis was performed using Agilent mouse miRNA v13 arrays. An miRNA Complete Labeling and Hyb Kit (Agilent Technologies) was used to label total RNA samples (100 ng) containing miRNAs with Cy3. Labeled samples were then applied to Agilent mouse miRNA v13 arrays and covered with an A4 
hybridization mixer. The arrays were then incubated for $12 \mathrm{~h}$ at $42^{\circ} \mathrm{C}$ in a MAUI 12-bay Hybridization System. The hybridized slides were washed by the method described above (Gene expression microarray analysis) and dried through centrifugation $(3,000 \mathrm{rpm}$, room temperature) [18].

\section{Gene expression microarray analysis}

Agilent mouse genome $4 \times 44 \mathrm{~K}$ arrays were use to profile gene expression in TM4 cells exposed to NP. Total RNA samples $(30 \mu \mathrm{g})$ from cells treated with $10 \mu \mathrm{g} / \mathrm{mL}$ NP were reverse transcribed using SuperScript (Invitrogen, CA, USA) in conjunction with dCTP labeled with Cyanine 3 (Cy3) or Cyanine 5 (Cy5) (NEN Life Science, CA, USA). The two resulting cDNA samples were combined in equal amounts. Each cDNA mixture was then applied to an Agilent mouse genome $4 \times 44 \mathrm{~K}$ array and covered with an A4 hybridization mixer (BioMicro Systems Inc., UT). The arrays were then incubated for $12 \mathrm{~h}$ at $42^{\circ} \mathrm{C}$ in a MAUI 12-bay Hybridization System (BioMicro Systems Inc) to allow hybridization. They were next washed in wash buffer $1(2 \times$ SSC, $0.1 \%$ SDS $)$ for $5 \mathrm{~min}$, in wash buffer $2(1 \times$ SSC) for $5 \mathrm{~min}$, and lastly, in wash buffer $3(0.2 \times$ SSC $)$ for $10 \mathrm{~min}$. Finally, they were dried through centrifugation (3,000 rpm, room temperature) [19].

\section{Microarray data analysis}

Hybridized arrays were scanned using a scanner (Agilent Technologies) and the resulting scanned images analyzed using the Feature Extraction Software (v10.7; Agilent Technologies). Expression profiling, clustering, gene ontology and GeneNetworks analyses were performed using GeneSpring GX (v11.0; Agilent Technologies). The microarray data were subjected to statistical analysis. Data acquisition and cut-off creation were used to obtain quantified data from the scanned images. For each spot, the median intensity rather than the mean, was calculated. Functional analysis of selected genes was performed through Gene Ontology (GO) analysis and using the KEGG Pathway Database, GeneSpring, and JAK software (GenoCheck Co. Ltd, Korea). Hierarchical clustering analysis of global gene expression patterns in different samples was performed using the GeneSpring Cluster 3.0 software (Euclidean distance and an average linkage algorithm were used). Data for chosen genes were analyzed by 1-way ANOVA analysis with time as the selected parameter. Multiple testing correction was achieved by Benjamini Hochberg false discovery rate (FDR).

\section{Prediction of miRNA targets and their functional classification}

miRNA target genes were identified using the GeneSpring software and then analyzed using the Ingenuity Pathway Analysis (IPA) software to identify their biological function and canonical pathways. Fisher's exact test was used to calculate statistical significance. We then compared the results for miRNAs with those for gene expression.

\section{Quantitative RT-PCR}

We selected two miRNAs that showed aberrant expression changes and validated and quantified them in a TaqMan miRNA assay (Applied Biosystems, CA, USA), performed using miRNA-specific primers according to the manufacturer's instructions. TM4 cells were treated with $10 \mu \mathrm{g} / \mathrm{ml} \mathrm{NP}$ for $24 \mathrm{~h}$ and total RNA was isolated using the TRIzol reagent. RNA quality was assessed using a 2100 Bioanalyzer. Duplicate total RNA samples were prepared from control and NP-treated cells and analyzed in triplicate by real-time PCR analysis, performed using a 7900 HT Fast Real-Time PCR System (Applied Biosystems). miRNA levels were calculated relative to average levels of target miRNAs and compared to controls after normalization to an internal control, snoRNA202. The amount of snoRNA202 in each sample was calculated from a standard curve.

\section{Results and Discussion}

\section{Cytotoxic effects of NP on TM4 cells}

We performed a cell viability assay using CCK-8 solution to evaluate the cytotoxic effects of NP on TM4 cells. The viability of TM4 cells was measured after growth in presence of NP $(0,3,5,10,20$ or $50 \mu \mathrm{g} / \mathrm{mL})$ for 3 or $24 \mathrm{~h}$. As shown in Figure 1-(A), the viability of TM4 cells exposed to NP for $24 \mathrm{~h}$ decreased, in a dose-dependent manner. Notably, we found that cytotoxicity was markedly increased in cells treated with NP at a concentration of 20 or $50 \mu \mathrm{g} / \mathrm{mL}$ at $24 \mathrm{~h}$ at both time points. We chose to use NP at a concentration of $10 \mu \mathrm{g} / \mathrm{mL}$ (which reduced cell viability to approximately $70 \%$ at $24 \mathrm{~h}$ ) in subsequent microarray analyses. The cytotoxic effects of NP were also confirmed by phase contrast microscopic analysis of TM4 cells treated with $10 \mu \mathrm{g} / \mathrm{mL} \mathrm{NP}$ for 3 and $24 \mathrm{~h}$. At $3 \mathrm{~h}$, there was no significant changes of cell morphology but cells exposed to NP for 24 h displayed morphological changes (e.g., irregular shape and cytoplasmic blebbing), were sparse, and detached from the culture plates on which they were growing (Figure 1-(B)). In addition, $\mathrm{LDH}$ assay showed that $\mathrm{LDH}$ released into the culture medium was significantly elevated after NP treatment (data not shown). The cytotoxic effect of NP in Sertoli cells was also consistent with the result of previous investigations [20].

\section{miRNA expression profiling in NP-treated TM4 cells}

To explore miRNA regulation in Sertoli cells following NP treatment, we performed miRNA expression analysis using Agilent mouse miRNA v13 arrays. miRNA expression profiling showed that exposure to NP significantly 


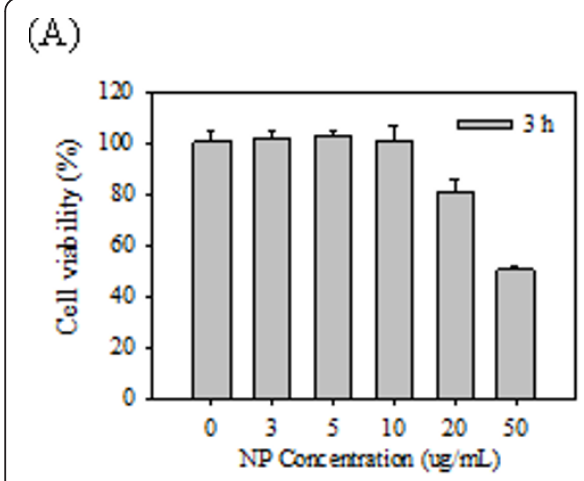

(B)
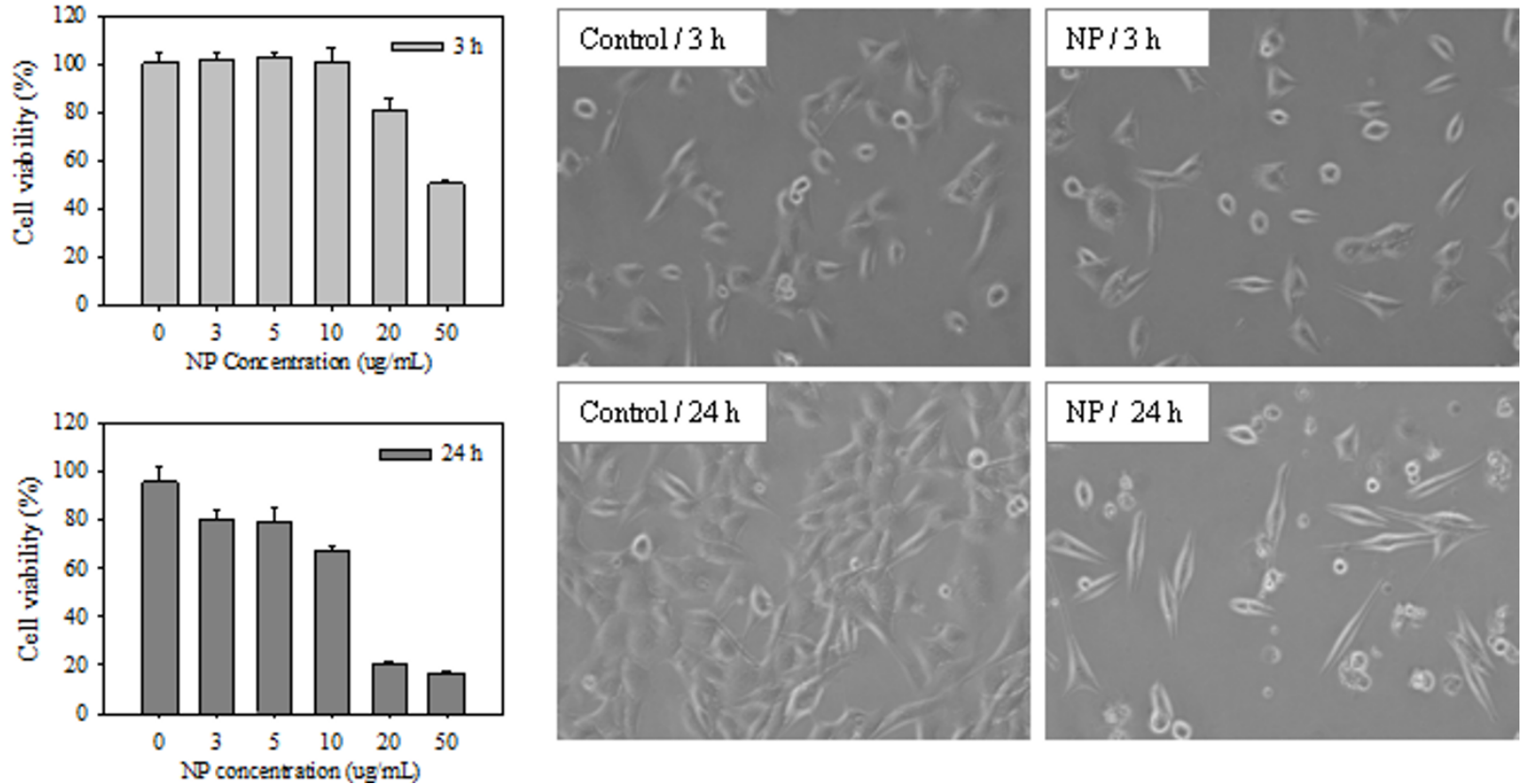

Figure 1 Cell viability of TM4 cells treated with NP and phase contrast microscope images. (A) Measurement of viability using CCK-8. All experiments consisted of three independent replicates, each performed at least in triplicate. Data are presented as the mean \pm SD. (B) Morphological observation of NP-treated TM4 cells. TM4 cells were treated with $10 \mu \mathrm{g} / \mathrm{ml} \mathrm{NP}$.

altered miRNA expression levels at $3 \mathrm{~h}$ and $24 \mathrm{~h}$. In total, 186 miRNAs were $>1.3$-fold up- or down-regulated following exposure to NP (59 at $3 \mathrm{~h}$ and 147 at $24 \mathrm{~h})$. We chose the cut-off condition with 1.3-fold $(P<$ 0.05 ) because a cut-off fold-change of 1.3 was considered as reasonable magnitude and statistical $P$ value is more important rather than the intensity for the analysis of miRNA expression changes. In addition, the false positive miRNAs were filtered out in the present study using multiple test corrections as described the method section. Hierarchical clustering of differentially expressed miRNAs revealed well-coordinated expression between sample groups (Additional file 1, Figure S1). The miRNAs that displayed differential expression in NP-treated cells at each time point are listed in Table 1. Most miRNAs the expression of which was altered in $\mathrm{NP}$-treated cells at $24 \mathrm{~h}$ were down-regulated. Of the 186 miRNAs the expression of which was altered, nine were up-regulated at both time points (miR-125a-3p, miR-297c, miR-421, miR-452, miR-483, miR-574-3p, miR-574-5p, miR-669a, miR-720) and 11 were downregulated at both time points (let-7g, miR-107, miR-10a, miR-15a, miR-15b, miR-199b*, miR-26a, miR-29c, miR324-5p, miR-331-3p, miR-342-3p). Two of the downregulated miRNAs, miR-15a and miR-15b, regulate the cell cycle by controlling the expression of BCL2 and several cyclin family members (D1, D2, E1) [21,22]. miR- 125a-3p and miR-107 are also involved in cell cycle and it is known that their expression is regulated by PPARA [23]. The functions of the other miRNAs the expression of which was altered at both time points remain unclear. Figure 2 shows the miRNAs the expression of which differed the most between NP-treated and control cells. Changes in miRNA expression at $3 \mathrm{~h}$ ranged from 11-fold down-regulation (miR-224) to 3.8-fold up-regulation (miR-367), and at $24 \mathrm{~h}$ from 7-fold down-regulation (miR-222) to 20.6-fold up-regulation (miR-135a*; Figure 2).

We performed quantitative RT-PCR (qRT-PCR) to confirm the expression levels of selected miRNAs. We chose miR-135a* and miR-199a-5p, two miRNAs that were found in microarray analyses to be highly up- and downregulated, respectively. qRT-PCR results showed that miR-135a* was up-regulated 1.9-fold and miR-199a-5p down-regulated approximately 1.7 -fold in independent experiments (Additional file 2, Figure S2). These up- or down expression patterns concurred with, but were more modest than, those detected in microarray analyses. The differences in the fold changes between microarray and qRT-PCR analyses may have been caused by differences in the principle between hybridization- and amplification-based methods. It can be also arisen from the inherently different gene sets during normalization between microarray and qRT-PCR. Several reports showed that 
Table 1 miRNAs the expression of which was altered following exposure to NP for 3 or $24 \mathrm{~h}$

\begin{tabular}{|c|c|c|}
\hline \multirow[b]{2}{*}{ Time point } & \multicolumn{2}{|l|}{ miRNAs } \\
\hline & Up-regulated & Down-regulated \\
\hline \multirow{2}{*}{$\begin{array}{l}3 \mathrm{~h} \\
(\mathrm{n}=59)\end{array}$} & $(n=35)$ & $(n=24)$ \\
\hline & 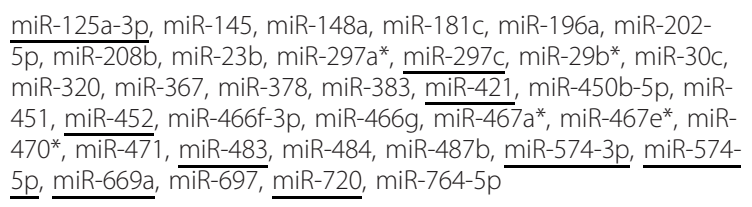 & 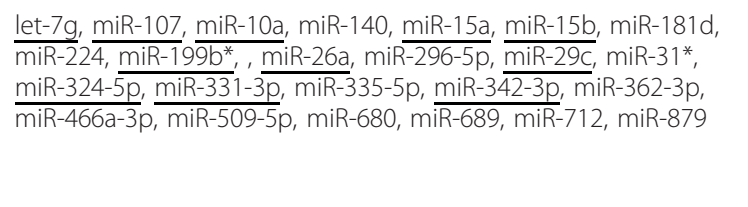 \\
\hline \multirow{2}{*}{$\begin{array}{l}24 h \\
(n=147)\end{array}$} & $(n=47)$ & $(n=100)$ \\
\hline & $\begin{array}{l}\text { let-7b, miR-101a, miR-125a-3p, miR-135a*, miR-139-3p, miR-142- } \\
\text { 5p, miR-146b*, miR-181a, miR-186*, miR-193, miR-195, miR-203, } \\
\text { miR-212, miR-297c, miR-30b*, miR-30c-2*, miR-335-5p, miR-362- } \\
\text { 5p, miR-380-3p, miR-382, miR-421, miR-448, miR-423-5p, miR-452, } \\
\text { miR-466c-5p, miR-467b*, miR-483, miR-509-5p, miR-568, miR-542- } \\
\text { 3p, miR-574-3p, miR-574-5p, miR-669a, miR-670, miR-671-5p, miR- } \\
\text { 680, miR-689, miR-709, miR-712, miR-719, miR-720, miR-721, miR- } \\
\text { 759, miR-802, miR-876-3p, miR-882, miR-883a-5p }\end{array}$ & $\begin{array}{l}\text { let-7a, let-7d, let-7e, let-7f, let-7g, let-7i, miR-101b, miR-103, miR- } \\
\frac{107}{126} \text { miR-10a, miR-10b, miR-122, miR-125a-5p, miR-125b-5p, miR- } \\
\text { 155, miR-15a, miR-15b, miR-16, miR-17*, miR-183, miR-186, miR- } \\
\text { 18a, miR-190, miR-193b, miR-196b, miR-199a-3p, miR-199a-5p, } \\
\text { miR-199b*, miR-19a, miR-208b, miR-20a, miR-21, miR-214, miR-22, } \\
\text { miR-221, miR-222, miR-23a, miR-23b, miR-24, miR-25, miR-26a, } \\
\text { miR-26b, miR-27a, miR-29a, miR-29b, miR-29b*, miR-29c, miR- } \\
\text { 301a, miR-30a, miR-30d, miR-30e, miR-31, miR-322, miR-323-3p, } \\
\text { miR-324-5p, miR-331-3p, miR-335-3p, miR-338-3p, miR-338-5p, } \\
\text { miR-340-5p, miR-342-3p, miR-345-5p, miR-34c, miR-350, miR-361, } \\
\text { miR-365, miR-367, miR-369-3p, miR-370, miR-374, miR-376b, miR- } \\
\text { 376c*,miR-378, miR-450b-3p, miR-453, miR-463, miR-466b-5p, } \\
\text { miR-466f-3p, miR-487b, miR-500, miR-582-5p, miR-652, miR-674*, } \\
\text { miR-682, miR-687, miR-690, miR-705, miR-706, miR-741, miR-92a*, } \\
\text { miR-875-5p, miR-93, miR-96, miR-99b }\end{array}$ \\
\hline
\end{tabular}

Numbers of miRNAs whose expression was altered by NP are shown in parentheses.

miRNAs whose expression was altered at both time points are underlined.

the number of true calls is greater than those calculated using qRT-PCR if the correlation is low between microarray and qRT-PCR [24]. The miRNAs can appear to be better-expressed in microarray analysis because microarray experiments employ normalization techniques within the miRNA population not by one reference gene.

Additionally, we created networks of differentially expressed miRNAs (Figure 3). At both 3 and 24 h postNP treatment, Ppara was found to be a core miRNAregulated gene. As mentioned above, Shah et al. reported that activated PPARA regulates miRNA expression in the mouse liver [23]. In TM4 cells exposed to NP, Ppara was down-regulated at both 3 and $24 \mathrm{~h}$. We thus surmised that miRNAs regulated by Ppara may include miR-378, miR-125a-3p, and miRNA-148a at $3 \mathrm{~h}$, and miR-20a, miR-203, and miR-101a at $24 \mathrm{~h}$.

\section{Gene expression profiling of NP-treated TM4 cells}

To evaluate the transcriptional regulation of target genes for miRNAs, we performed gene expression profiling using Agilent mouse whole genome $4 \times 44 \mathrm{~K}$ arrays. The data generated were further combined with miRNA expression data in each time point. Each data set consisted of data from three samples each from NP-treated and control cells for each time point ( 3 and $24 \mathrm{~h}$ ). At 3 and $24 \mathrm{~h}$, 680 and 1,787 genes, respectively, were differentially expressed in NP-treated and control cells (fold-change $>2 ; P<0.05$, Welch's $t$-test). Of the genes the expression of which was altered in cells exposed to NP, 291 genes exhibited altered expression at both time points tested. We also analyzed gene expression using hierarchical clustering (evaluated by 1 -way ANOVA; $P<0.05$ ) to allow visual biological interpretation of the gene expression patterns. The results of this clustering analysis showed that the samples clustered according to time point and that gene expression patterns varied according to length of exposure to NP (Additional file 3, Figure S3). Functional analysis of the differentially expressed genes was performed using the GO database. These results are shown in Table 2. In total, 535 and 1,559 genes the expression of which was altered in cells treated with NP for 3 and $24 \mathrm{~h}$, respectively, were functionally annotated with GO terms. The expression of genes with roles in signal transduction, transport, and transcription was highly altered in cells treated with NP for $3 \mathrm{~h}$. The expression of genes with roles in growth, homeostasis, gametogenesis, spermatogenesis, and behavior was significantly altered in cells treated with NP for $24 \mathrm{~h}$ comparing to that of $3 \mathrm{~h}$ treated cells. Notably, the numbers of differentially expressed genes with roles in gametogenesis and spermatogenesis were highly increased at $24 \mathrm{~h}$. Among genes with roles in gametogenesis and spermatogenesis, Rps6ka2 (ribosomal 
(A)

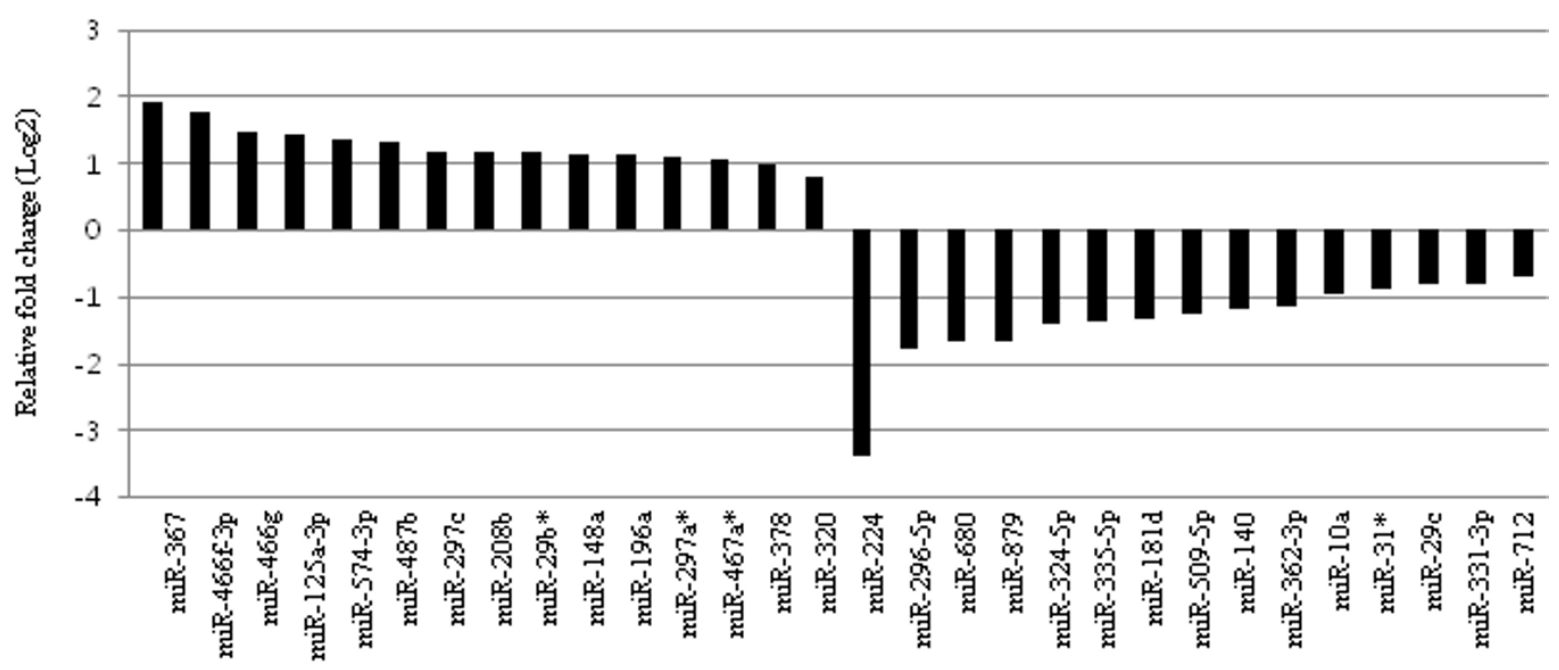

(B)

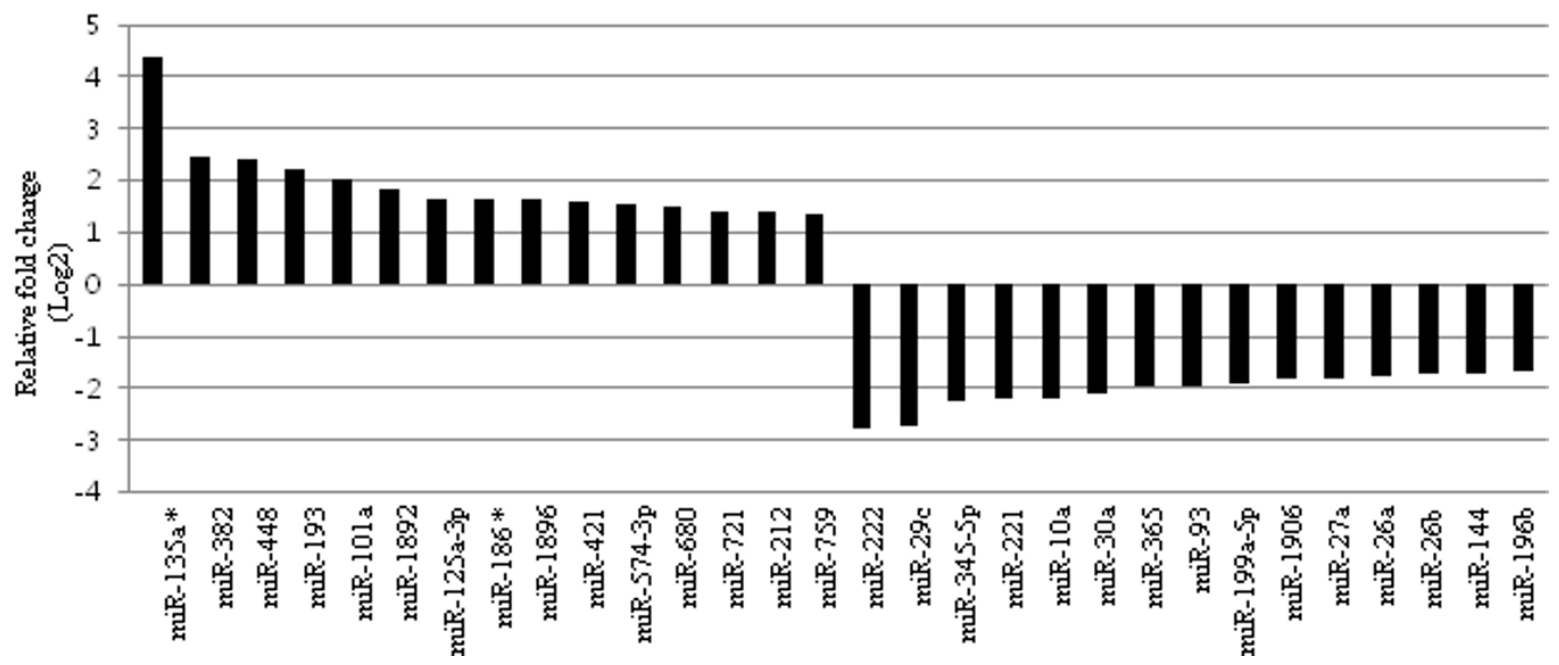

Figure 2 Expression fold changes for the most highly deregulated miRNAs in NP-treated TM4 cells. (A) 3 h. (B) 24 h.

protein S6 kinase, polypeptide 2), Afp (alpha fetoprotein), Tbpl1 (TATAbox binding protein-like 1), and Mast2 (15 days embryo head cDNA) were up-regulated in NP-treated TM4 cells, while Tssk1 (testis-specific serine kinase 1), Ereg (epiregulin), and Adam 25 (testase 2) were downregulated in NP-treated TM4 cells.

\section{Comprehensive prediction of target genes for deregulated miRNAs}

To comprehensively identify target genes, we used the GeneSpring GX v11.0 software. It is known that miRNAs target multiple genes and that target genes can be regulated by negative or positive feedback mechanisms. Before analyzing the target genes for miRNAs the expression of which was altered in NP-treated cells, we filtered the target gene set to include only genes the expression of which showed the opposite pattern to that of the corresponding miRNAs. In total, 338 and 1,024 miRNA target genes were down-regulated at 3 and $24 \mathrm{~h}$ post-NP treatment, respectively (with the corresponding miRNAs being up-regulated). 146 and 3,128 target genes were up-regulated at 3 and $24 \mathrm{~h}$ post-NP treatment (with the corresponding miRNAs being down-regulated).

The detected target genes were categorized according to biological function using Ingenuity Pathway Analysis (IPA) software. The top-ranked biological functions of miRNA target genes in NP-treated TM4 cells are shown in Figure 4. Biofunctional analysis showed that target genes for differentially regulated miRNAs were, as expected, primarily involved in the control of cellular 
(A)

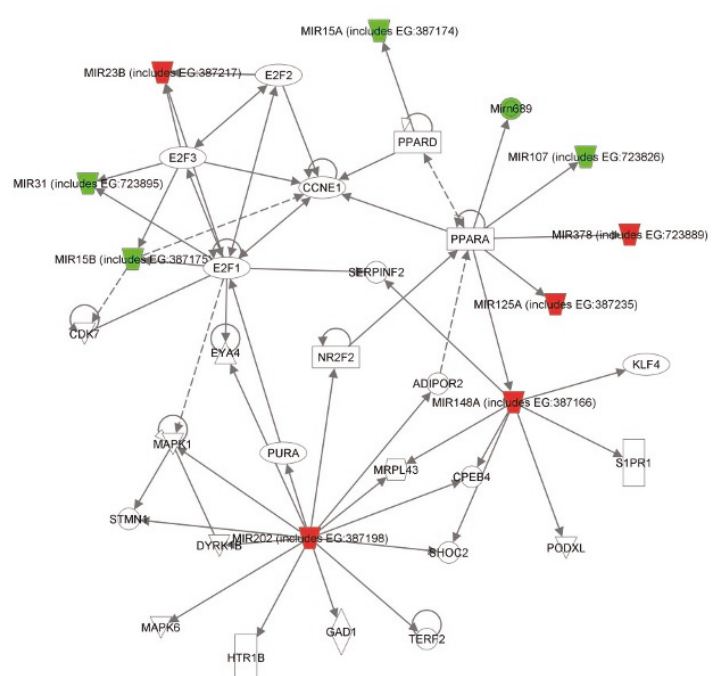

(B)

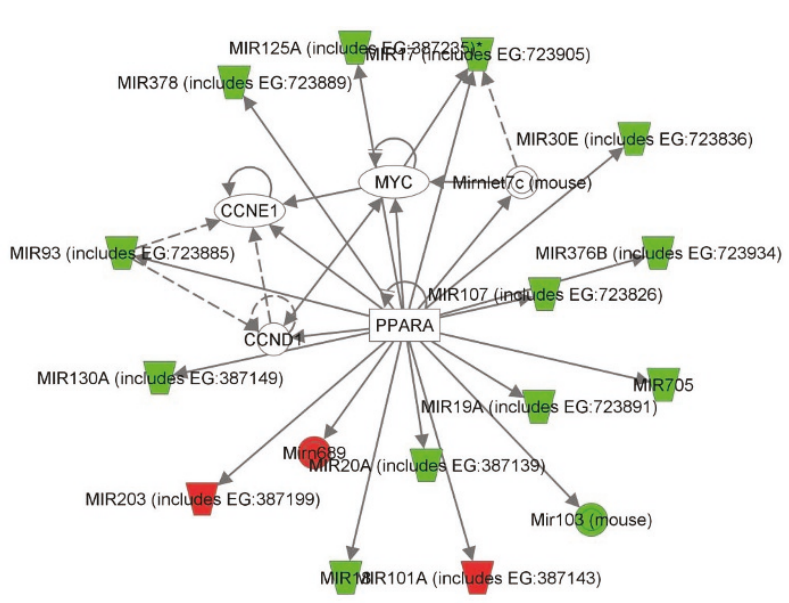

Figure 3 Network analysis of miRNAs the expression of which in TM4 cells was altered by NP (A) 3 h. (B) 24 h. Network analysis was performed using an algorithm supported by IPA. A best-matched network map was created.

growth and proliferation, the cell cycle, and cell death. At $3 \mathrm{~h}$ post-NP-treatment, target genes implicated in growth and proliferation, tissue development, and

Table 2 Functional classification of genes the expression of which in TM4 cells was modulated by NP

\begin{tabular}{lll}
\hline Function & No. of genes & \\
& $\mathbf{3} \mathbf{~ h}$ & $\mathbf{2 4} \mathbf{~ h}$ \\
\hline Transport & 77 & 278 \\
Signal transduction & 102 & 250 \\
Transcription & 73 & 169 \\
Cell differentiation & 38 & 119 \\
Cell cycle & 28 & 100 \\
Response to stress & 38 & 78 \\
Lipid metabolism & 20 & 75 \\
Apoptosis & 28 & 70 \\
Cell adhesion & 23 & 70 \\
Behavior & 11 & $59^{*}$ \\
Cell proliferation & 19 & 54 \\
Protein biosynthesis & 18 & 54 \\
Immune response & 20 & 42 \\
Angiogenesis & 10 & 29 \\
Homeostasis & 7 & 28 \\
Growth & 6 & 26 \\
Cell-cell signaling & 7 & 19 \\
Gametogenesis & 3 & $17^{*}$ \\
Spermatogenesis & 1 & $12^{*}$ \\
Inflammatory response & 6 & 10 \\
Total number of genes & $\mathbf{5 3 5}$ & $\mathbf{1 , 5 5 9}$ \\
\hline
\end{tabular}

*Number of genes hit into the categories remarkably increased (over 5-fold) at $24 \mathrm{~h}$ comparing to at $3 \mathrm{~h}$ genetic disorders were down-regulated by miRNAs, while several genes linked to RNA damage and repair were up-regulated to repair the cellular damage sustained. Because of the cytotoxic effects of NP, most target genes related to cell cycle or cell death were differentially expressed at $24 \mathrm{~h}$ post-NP treatment.

\section{Functional analysis of miR-135a* target genes}

miR-135a* was significantly up-regulated after exposure to NP for $24 \mathrm{~h}$. The change in miR-135a* expression was the highest in this study (20.6-fold up-regulation). We thus suggest that miR-135a* may play important roles following NP exposure. Through categorization of its target genes, we identified its potential molecular and cellular roles as being cell cycle, cell death, cell morphology, cell-to-cell signaling and interaction, and cellular assembly and organization (Table 3). Down-regulated miR-135a* target genes are listed in Table 4. Canonical pathway analysis of these genes showed that the expression of genes linked to the production of nitric oxide (NO) and reactive oxygen species (ROS; Ncf2 and Ppp2r2b), Wnt/ $\beta$-catenin signaling (Wnt1), and ERK/ MAP kinase signaling (Rapget3) could be down-regulated by miR-135a* in response to NP exposure

In the canonical pathway, its candidate targets fall into several categories. Genes implicated in the production of NO and ROS were predicted to be miR-135a* targets. There have been reports that NP suppresses cell growth and cellular respiration in yeast cells by inducing ROS generation, and the formation of hydroxyl radicals in rat brain striatum $[25,26]$. Recently, NP was shown to 
$(\mathrm{A})$

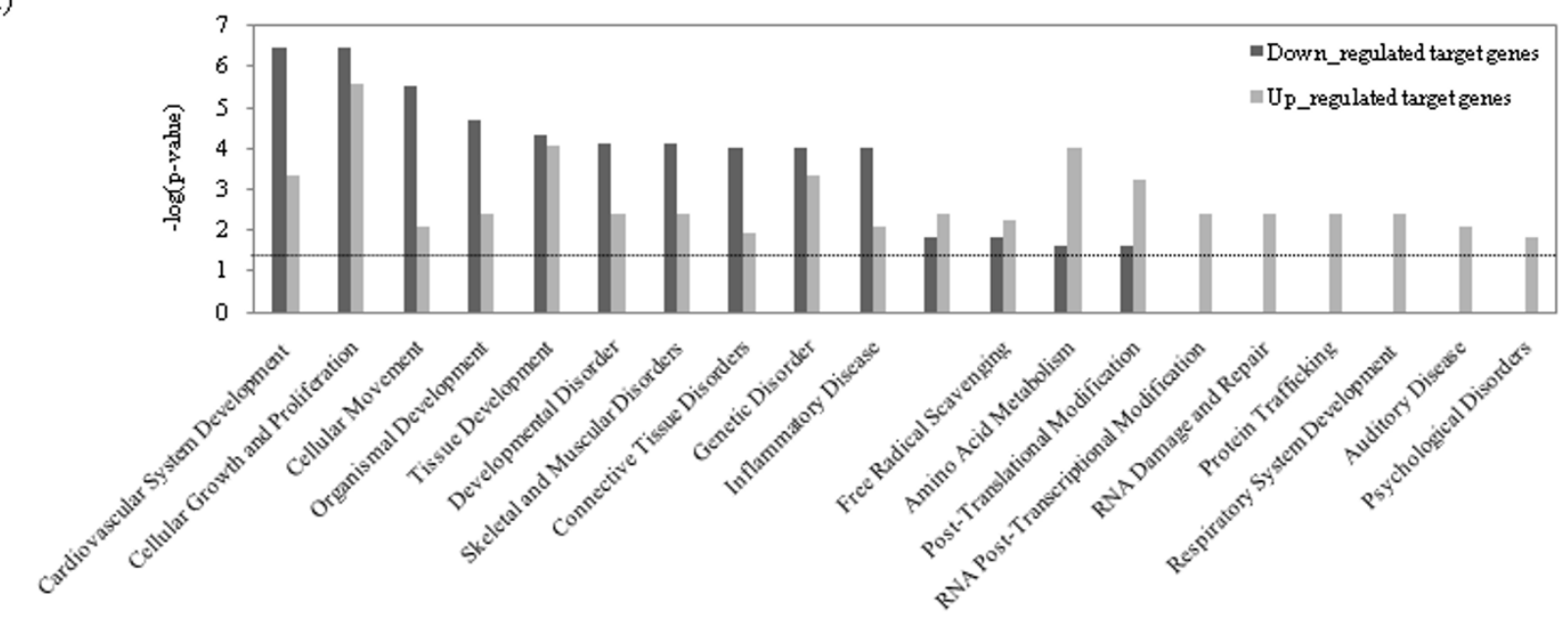

(B)
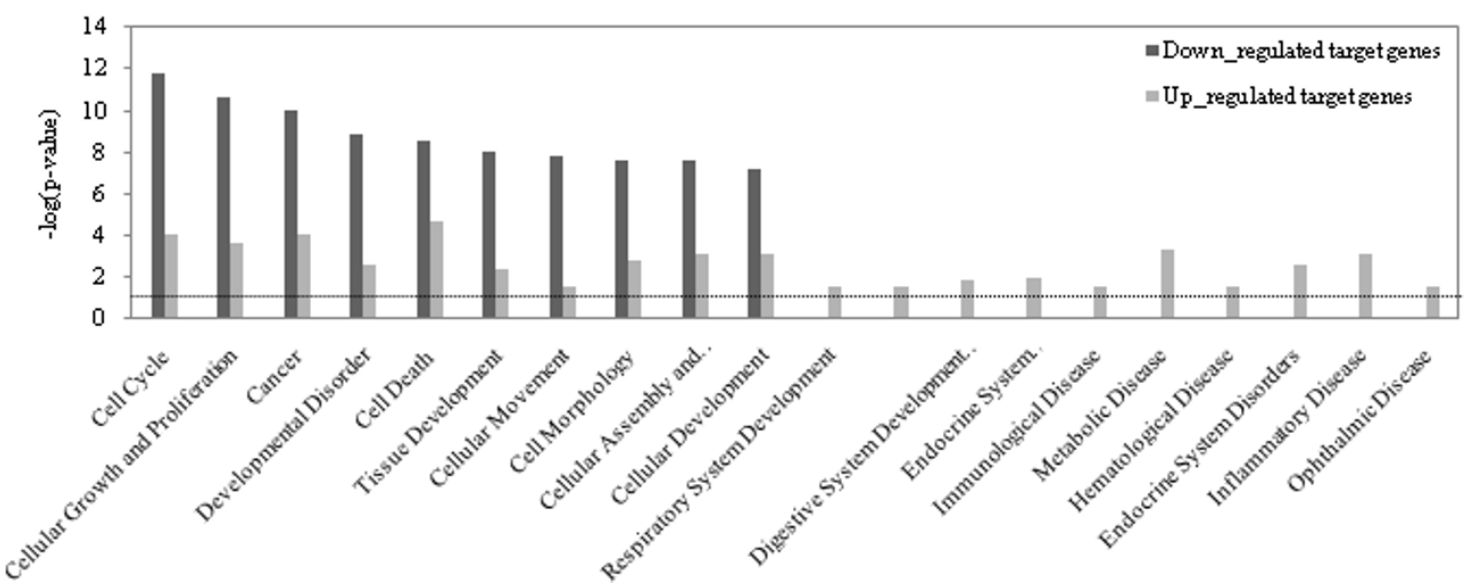

Figure 4 The top 10 ranked biological functions miRNA target genes. (A) Target genes the expression of which was down- or up-regulated at $3 \mathrm{~h}$ (B) Target genes the expression of which was down- or up-regulated at $24 \mathrm{~h}$. The dotted line indicates the threshold for statistical significance $(P<0.05)$.

induce ROS generation in human blood neutrophils and rat Sertoli cells through the activation of signal transduction pathways [20,27]. NP increases ROS levels and lipid peroxidation and decreases the activity of antioxidant enzymes in the rat testis [28]. The results of the present study further suggest that mouse Sertoli cells are also affected by NP-induced ROS. We do not know the precise mechanism of NP-induced ROS generation in mouse Sertoli cells; this subject requires further investigation.

Other predicted target genes influence Wnt $/ \beta$-catenin signaling. The $\mathrm{Wnt} / \beta$-catenin signaling pathway is known to play fundamental roles in the regulation of proliferation, regeneration, and differentiation in many tissues and types

Table 3 Functional classification of miR-135a* target genes

\begin{tabular}{lll}
\hline Molecular and cellular functions & & No. of genes \\
\hline Name & $P$-value & 7 \\
\hline Cell Cycle & $2.48 \mathrm{E}-04-1.72 \mathrm{E}-02$ & 7 \\
Cell Death & $1.02 \mathrm{E}-03-4.78 \mathrm{E}-02$ & 3 \\
Cell Morphology & $1.02 \mathrm{E}-03-4.69 \mathrm{E}-02$ & 4 \\
Cell-To-Cell Signaling and Interaction & $1.02 \mathrm{E}-03-4.78 \mathrm{E}-02$ & 2 \\
Cellular Assembly and Organization & $1.02 \mathrm{E}-03-4.00 \mathrm{E}-02$ & \\
\hline
\end{tabular}




\begin{tabular}{|c|c|c|c|c|}
\hline Gene symbol & Gene title & Acc. No & Fold change & GO category \\
\hline Nasp & Nuclear autoantigenic sperm protein (histone-binding) & NM_016777 & -1.05 & Cell cycle, Cell proliferation \\
\hline Rapgef3 & Rap guanine nucleotide exchange factor (GEF) 3 & NM_144850 & -1.82 & Intracellular signaling cascade \\
\hline Ncf2 & Neutrophil cytosolic factor 2 & NM_010877 & -1.43 & Superoxide metabolic process \\
\hline Ywhaq & Tyrosine 3-monooxygenase/tryptophan 5-monooxygenase activation protein, theta polypeptide & AK170335 & -1.82 & Signal transduction \\
\hline E330013P04Rik & RIKEN cDNA E330013P04 gene & BC076607 & -1.08 & \\
\hline Ddah1 & Dimethylarginine dimethylaminohydrolase 1 & NM_026993 & -1.55 & Nitric oxide biosynthetic process \\
\hline Ppp2r2b & Protein phosphatase 2 , regulatory subunit $B$, beta isoform & NM_028392 & -1.69 & Signal transduction \\
\hline Cyp2c40 & Cytochrome P450, family 2, subfamily c, polypeptide 40 & NM_010004 & -1.46 & Oxidation reduction \\
\hline Rttn & Rotatin & AK015013 & -1.11 & Multicellular organismal development \\
\hline Slc10a7 & Solute carrier family 10 , member 7 & NM_029736 & -1.22 & Ion transport \\
\hline Aspm & Asp (abnormal spindle)-like, microcephaly associated & NM_009791 & -1.82 & Cell cycle \\
\hline Tmem108 & Transmembrane protein 108 & AK039631 & -1.98 & Biological process unknown \\
\hline Tpm1 & Tropomyosin 1, alpha & NM_024427 & -1.84 & Embryonic development \\
\hline 1700074P13Rik & RIKEN CDNA 1700074P13 gene & NM_028550 & -1.55 & Biological process unknown \\
\hline Wnt1 & Wingless-related MMTV integration site 1 & NM_021279 & -1.17 & Wnt receptor signaling pathway \\
\hline Crip3 & Cysteine-rich protein 3 & NM_053250 & -1.33 & T cell proliferation \\
\hline Zfr & Zinc finger RNA binding protein & AK037578 & -1.06 & Multicellular organismal development \\
\hline Mmpla & Matrix metallopeptidase 1a (interstitial collagenase) & NM_032006 & -1.04 & Proteolysis, Collagen catabolic process \\
\hline Olfr1309 & Olfactory receptor 1309 & NM_146447 & -1.49 & Signal transduction \\
\hline Nfic & Nuclear factor I/C & NM_008688 & -1.17 & Regulation of transcription \\
\hline
\end{tabular}


of cells, including stem cells. Although there have been few reports on possible relationships between NP exposure and Wnt/ $\beta$-catenin signaling, we suggest that key cell functions may be affected by altered expression of Wnt $/ \beta$ catenin signaling pathway-related genes.

miR-135a* may target ERK/MAP kinase signalingrelated genes. MAP kinases are known to be key regulators of cell differentiation, proliferation and apoptosis [29]. A study showed that $17 \beta$-estradiol and structurally diverse estrogenic compounds, including bisphenol A and NP, activated MAP kinases in MCF-7 cells [30]. Further, the three major MAPK subfamilies (ERK, JNK, and p38 MAPK) were activated by NP in SCM1 human gastric cancer cells. Notably, NP induced apoptosis by activating a $\mathrm{Ca}^{2+}$ - and p38 MAPK-dependent signaling pathway. Although the effects of ERK during cell death remain unclear, there is a suggestion that it may promote cell survival [31]. Indeed, the activation of ERK was shown to increase neuronal survival in retinal ganglion cells [32]. Based on the results of these previous studies, we suggest that the activation of ERK/MAP kinase signaling may also promote the survival of Sertoli cells. We believe that these tentative conclusions warrant further investigation and hope that future studies we will increase our understanding of the mechanisms of NP-induced miRNA-mediated cytotoxicity in mouse Sertoli cells.

\section{Conclusions}

Recently, it has been reported that xenoestrogenic compounds, including NP, cause reproductive toxicity in males (e.g., a decline in semen quality). Here, to evaluate the mode of action of NP on the male reproductive system, we comprehensively evaluated mRNA and miRNAs expression profiles in NP-exposed mouse TM4 Sertoli cells through microarray analysis. Exposure of TM4 Sertoli cells to NP significantly altered miRNA expression levels. By analyzing the biofunctions of both deregulated miRNAs and their target genes, we obtained information about genes regulated by miRNAs. Additionally, core miRNAs and target genes deregulated in NP-treated cells were identified through functional and network analyses of miRNAs and target genes. Although further studies are required to determine the function of these selected miRNAs, this information may aid in understanding the epigenomic regulation of toxicity in Sertoli cells exposed to NP and could support the risk assessment of environmental estrogenic compounds.

\section{Additional material}

Additional file 1: Supplemental Figure S1: Hierarchical clustering of miRNA expression profiles in NP-treated TM4 cells.

Additional file 2: Supplemental Figure S2: Validation of miR-135* and miR-199a-5a levels by qRT-PCR.
Additional file 3: Supplemental Figure S3: Hierarchical clustering of the gene expression profiles in NP-treated TM4 cells.

\section{Acknowledgements}

This work was supported an Eco-Technopia 21 project grant from the Ministry of Environment (Development of Decision Method of Chromosomal Abnormality in Reproductive System by Toxic Substances at the Korea Institute of Toxicology).

\section{Author details}

'Division of Research and Development, Korea Institute of Toxicology, 19 Shinsung-ro, Yuseong, Daejeon, 305-343, Korea. ${ }^{2}$ GenoCheck Co., Ltd. \& Hanyang University, Sa 3-dong, Sangnok-gu, Ansan, Gyeonggi-do, 426-791, Korea.

\section{Authors' contributions}

$J C$ analyzed the microarray data and drafted the manuscript. JO designed and performed the overall experiments and helped to finalize the manuscript. MC, HP, SP and SK contributed to the sampling and performed the microarray experiments. SK performed the real-time PCR for validation and participated in statistical analysis. $\mathrm{MO}$ and $\mathrm{SH}$ participated in overall design of microarray analysis. SY designed and coordinated the overall study as a corresponding author and helped to draft the manuscript. All authors read and approved the final manuscript.

\section{Competing interests}

The authors declare that they have no competing interests.

Received: 25 April 2011 Accepted: 14 September 2011

Published: 14 September 2011

\section{References}

1. Vazquez-Duhalt R, Marquez-Rocha F, Ponce E, Licea AF, Viana MT: Nonylphenol, an integrated vision of a pollutant. Ecol Environ Res 2005, 4(1):1-25.

2. Soares A, Guieysse B, Jefferson B, Cartmell E, Lester JN: Nonylphenol in the environment: a critical review on occurrence, fate, toxicity and treatment in wastewaters. Environ Int 2008, 34(7):1033-1049.

3. Lee $P C$, Lee $W$ : In vivo estrogenic action of nonylphenol in immature female rats. Bull Environ Contam Toxicol 1996, 57(3):341-348.

4. White R, Jobling S, Hoare SA, Sumpter JP, Parker MG: Environmentally persistent alkylphenolic compounds are estrogenic. Endocrinology 1994, 135(1):175-182.

5. Alberts E, Kalverboer AF, Hopkins B: Mother-infant dialogue in the first days of life: an observational study during breast-feeding. $J$ Child Psychol Psychiatry 1983, 24(1):145-161.

6. Lee HJ, Chattopadhyay S, Gong EY, Ahn RS, Lee K: Antiandrogenic effects of bisphenol $\mathrm{A}$ and nonylphenol on the function of androgen receptor. Toxicol Sci 2003, 75(1):40-46.

7. Hughes PJ, McLellan H, Lowes DA, Kahn SZ, Bilmen JG, Tovey SC, Godfrey RE, Michell RH, Kirk CJ, Michelangeli F: Estrogenic alkylphenols induce cell death by inhibiting testis endoplasmic reticulum $\mathrm{Ca}(2+)$ pumps. Biochem Biophys Res Commun 2000, 277(3):568-574.

8. Oh JH, Oh MJ, Park HJ, Kim SJ, Park SM, Yoon HJ, Cho JW, Hwang SY, Yoon S: Analysis of gene expression in the testes of mice exposed to bisphenol A and nonylphenol. Biochip J 2009, 3(1):12-20.

9. Philippidou D, Schmitt M, Moser D, Margue C, Nazarov PV, Muller A, Vallar L, Nashan D, Behrmann I, Kreis S: Signatures of microRNAs and selected microRNA target genes in human melanoma. Cancer Res 2010, 70(10):4163-4173.

10. Gueta K, Molotski N, Gerchikov N, Mor E, Savion S, Fein A, Toder V, Shomron N, Torchinsky A: Teratogen-induced alterations in microRNA34, microRNA-125b and microRNA-155 expression: correlation with embryonic p53 genotype and limb phenotype. BMC Dev Biol 2010, 10:20.

11. Lewis $B P$, Burge $C B$, Bartel DP: Conserved seed pairing, often flanked by adenosines, indicates that thousands of human genes are microRNA targets. Cell 2005, 120(1):15-20. 
12. Liu DZ, Tian Y, Ander BP, Xu H, Stamova BS, Zhan X, Turner RJ, Jickling G, Sharp FR: Brain and blood microRNA expression profiling of ischemic stroke, intracerebral hemorrhage, and kainate seizures. J Cereb Blood Flow Metab 2010, 30(1):92-101.

13. Zhang $B$, Pan $X:$ RDX induces aberrant expression of microRNAs in mouse brain and liver. Environ Health Perspect 2009, 117(2):231-240.

14. Fukushima T, Hamada Y, Yamada H, Horii I: Changes of micro-RNA expression in rat liver treated by acetaminophen or carbon tetrachloride-regulating role of micro-RNA for RNA expression. J Toxicol Sci 2007, 32(4):401-409.

15. Wang K, Zhang S, Marzolf B, Troisch P, Brightman A, Hu Z, Hood LE, Galas DJ: Circulating microRNAs, potential biomarkers for drug-induced liver injury. Proc Natl Acad Sci USA 2009, 106(11):4402-4407.

16. Griswold MD: The central role of Sertoli cells in spermatogenesis. Semin Cell Dev Biol 1998, 9(4):411-416.

17. Sharpe RM, McKinnell C, Kivlin C, Fisher JS: Proliferation and functional maturation of Sertoli cells, and their relevance to disorders of testis function in adulthood. Reproduction 2003, 125(6):769-784.

18. Paul S, Kim SJ, Park HW, Lee SY, An YR, Oh MJ, Jung JW, Hwang SY: Alteration in miRNA expression profiling with response to nonylphenol in human cell lines. Mol Cell Toxicol 2009, 5:67-74.

19. Cho HS, Kim SJ, Park HW, Oh MJ, Yu SY, Lee SY, Park CS, Han JR, Oh JH, Hwang SYY, S S: A relationship between miRNA and gene expression in the mouse sertoli cell line after exposure to bisphenol A. Biochip J 2010 4(1):75-81.

20. Gong Y, Han XD: Nonylphenol-induced oxidative stress and cytotoxicity in testicular Sertoli cells. Reprod Toxicol 2006, 22(4):623-630.

21. Yin KJ, Deng Z, Hamblin M, Xiang Y, Huang H, Zhang J, Jiang X, Wang Y, Chen YE: Peroxisome proliferator-activated receptor delta regulation of miR-15a in ischemia-induced cerebral vascular endothelial injury. $J$ Neurosci 2010, 30(18):6398-6408.

22. Bueno MJ, Gomez de Cedron M, Laresgoiti U, Fernandez-Piqueras J, Zubiaga AM, Malumbres M: Multiple E2F-induced microRNAs prevent replicative stress in response to mitogenic signaling. Mol Cell Biol 2010, 30(12):2983-2995.

23. Shah YM, Morimura K, Yang Q, Tanabe T, Takagi M, Gonzalez FJ: Peroxisome proliferator-activated receptor alpha regulates a microRNAmediated signaling cascade responsible for hepatocellular proliferation. Mol Cell Biol 2007, 27(12):4238-4247

24. Git A, Dvinge H, Salmon-Divon M, Osborne M, Kutter C, Hadfield J, Bertone $P$, Caldas C: Systematic comparison of microarray profiling, realtime $\mathrm{PCR}$, and next-generation sequencing technologies for measuring differential microRNA expression. RNA 2010, 16(5):991-1006.

25. Okai Y, Higashi-Okai K, Machida K, Nakamura H, Nakayama K, Fijita K, Tanaka T, Taniguchi M: Protective effects of alpha-tocopherol and betacarotene on para-nonylphenol-induced inhibition of cell growth, cellular respiration and glucose-induced proton extrusion of bacteria. FEMS Microbiol Lett 2000, 187(2):161-165.

26. Obata T, Kubota S: Formation of hydroxy radicals by environmental estrogen-like chemicals in rat striatum. Neurosci Lett 2000, 296(1):41-44.

27. Okai Y, Sato EF, Higashi-Okai K, Inoue M: Enhancing effect of the endocrine disruptor para-nonylphenol on the generation of reactive oxygen species in human blood neutrophils. Environ Health Perspect 2004, 112(5):553-556.

28. Chitra KC, Mathur PP: Vitamin E prevents nonylphenol-induced oxidative stress in testis of rats. Indian J Exp Biol 2004, 42(2):220-223.

29. Lefloch R, Pouyssegur J, Lenormand P: Single and combined silencing of ERK1 and ERK2 reveals their positive contribution to growth signaling depending on their expression levels. Mol Cell Biol 2008, 28(1):511-527.

30. Li X, Zhang S, Safe S: Activation of kinase pathways in MCF-7 cells by 17beta-estradiol and structurally diverse estrogenic compounds. J Steroid Biochem Mol Biol 2006, 98(2-3):122-132.

31. Kuo CC, Kuo DH, Huang CJ, Fang YC, Shieh P, Chen FA, Shaw CF, Jan CR: Nonylphenol -induced apoptosis pathways in SCM1 human gastric cancer cells. Drug Dev Res 2010, 71:139-148

32. Lin HJ, Chao PD, Huang SY, Wan L, Wu CJ, Tsai FJ: Aloe-emodin suppressed NMDA-induced apoptosis of retinal ganglion cells through regulation of ERK phosphorylation. Phytother Res 2007, 21(11):1007-1014. doi:10.1186/1477-7827-9-126

Cite this article as: Choi et al:: miRNA regulation of cytotoxic effects in mouse Sertoli cells exposed to nonylphenol. Reproductive Biology and Endocrinology 2011 9:126.

\section{Submit your next manuscript to BioMed Central and take full advantage of:}

- Convenient online submission

- Thorough peer review

- No space constraints or color figure charges

- Immediate publication on acceptance

- Inclusion in PubMed, CAS, Scopus and Google Scholar

- Research which is freely available for redistribution 